\title{
Study of physiological and quality parameters during development and ripening of pepino (Solanum muricatum Aiton) fruit
}

\author{
Carolina Contreras ${ }^{1}$, Wilfried Schwab ${ }^{2}$, Mechthild Mayershofer ${ }^{2}$, Ignacio Morales ${ }^{3}$, \\ Mauricio Gonzalez-Agüero ${ }^{3}$, and Bruno G. Defilippi ${ }^{3 *}$ \\ 'Pontificia Universidad Católica de Chile, Facultad de Agronomía e Ingeniería Forestal, Departamento de Fruticultura y Enología, \\ Vicuña Mackenna 4860, PO Box 7820436, Santiago, Chile. \\ ${ }^{2}$ Technical University of Munich, Center of Life and Food Science Weihenstephan, Biotechnology of Natural Products, Liesel- \\ Beckmann-Str. 1,85354 Freising, Germany. \\ ${ }^{3}$ Instituto de Investigaciones Agropecuarias, INIA La Platina, Santa Rosa 11610, Santiago, Chile. \\ "Corresponding author (bdefilip@inia.cl).
}

Received: 27 November 2018; Accepted: 15 March 2019; doi:10.4067/S0718-58392019000300385

\begin{abstract}
Pepino (Solanum muricatum Aiton) fruit served as an important crop in Pre-Columbian Andean cultures. Despite the fact that pepino has been known for centuries, information about maturity indices and physiological quality parameters of its fruit is scarce. The objective was to increase our knowledge of pepino fruit physiology and maturity to improve fruit handling and storage. Pepino fruit were studied during 2015 and 2016 seasons. During 2015, developmental and maturity studies were carried out, whereas in 2016 the developmental study was repeated. Twenty-five fruit were analyzed during six developmental stages ranging from immature (stage 1) to senescent fruit (stage 6). Fruit were analyzed for soluble solid content (SSC), titratable acidity (TA), color, respiration and ethylene production, soluble sugars, organic acids, and aroma. For the maturity assay, nonsignificant differences were found between green background color (M1) and white background color (M2) in the different quality parameters, with the exception of firmness. Pepino is a non-climacteric fruit with a low ethylene production rate. Unlike foreign cultivars, Chilean pepinos have low amounts of citric acid, being the predominant acids: malic and quinic. Out of 22 volatile compounds identified in this study, the predominant aroma volatiles are 3-methyl-3-butenyl acetate and 3-methyl-2-butenyl acetate from the terpenoid pathway, and trans-2-hexenal from the lipoxygenase pathway. The quality parameters changing in a ripening-dependent manner were firmness, SSC, aroma and color. Other parameters such as TA and organic acids stayed constant throughout development. In addition to color and SSC, this study also suggests aroma as a harvest index.
\end{abstract}

Key words: Aroma, firmness, fruit ripening, harvest index, maturity, sucrose.

\section{INTRODUCTION}

Pepino (Solanum muricatum Aiton) is an aromatic, sweet and succulent fleshy fruit. It is presumed that pepino genetic center of origin lies in southern Colombia (Anderson et al., 1996) and from there, it was expanded to the rest of South America through the Inca Empire, which expanded from Colombia southern border until central Chile just below Santiago (National Research Council, 1989). In the last decades, several countries have investigated pepino as a potential 'new' species to introduce in their fresh markets, and envisioned the need of breeding programs for crop adaptation to new agroclimatic conditions and fruit organoleptic traits. Therefore, three countries have directed their efforts on the genetic improvement of pepino crop through their breeding programs: New Zealand (Wratt and Smith, 1983), Spain (RodríguezBurruezo et al., 2004b), and Israel (Levy et al., 2006). 
The first genetic material introduced to New Zealand was in 1973 from Chile and Ecuador, and the main purpose was to diversify the consumer market by introducing exotic species from South America. Thus, the New Zealand breeding program carried out in the 1970s was mainly focused on fruit quality, crop yield and field resistance to root rot (Phytophtora citricola) and to late blight (Phytophtora infestans) (Wratt and Smith, 1983). The Spanish and Israeli breeding programs were developed in the 1990s and 2000s, respectively; and they pursued the development of cultivars well-adapted to their climates and to improve the fruit quality by increasing aroma and sugar/acid contents. As a result of these breeding efforts, New Zealand released the commercial cultivars Miski, Kawi, Suma, Asca, Schmidt, Lincoln Gold, Lincoln Long, Golden Litestripe plus $\sim 80$ clonal selections. The Spanish breeding program released the pepino cultivars Turia, Puzol, Valencia, Sweet Round and Sweet Long, and Israel the cultivars Pepo, Rosy, Becky, Hannah, Nitza, and Tally. Unfortunately, these breeding programs had a modest success for introducing the new pepino cultivars in the markets. Possible reasons for this limited success included the time required for fruit ripening (Prohens et al., 1996) and its low organoleptic quality, which does not meet consumer standards (e.g. fruit with $8 \%$ soluble solid content is considered too low sugar content by the European market) (Kola et al., 2015). In addition, other reasons were the poor handling and inadequate storage treatments (Huyskens-Keil et al., 2001; Rodríguez-Burruezo et al., 2011). Whereas in New Zealand main reasons included poor fruit set due to pollen longevity and viability (Morley-Bunker, 1983), which led to low yields of the pepino production.

The pepino crop currently cultivated in Chile corresponds to selections or native accessions that have undergone natural domestication over the years, therefore, there are currently no registered cultivars (Bravo and Arias, 1983). It has been cultivated in the northern part of the country, and is commonly associated to a coastal climate, higher relative humidity, mild summers, and poor soils (Bravo and Arias, 1983). The pepino plant is vegetatively propagated by stem cutting and cultivated annually due to frost sensitivity (Contreras et al., 2016). Pepino is considered an easy-to-grow plant and economically profitable crop, and despite the limited available information about this crop, pepinos have been cultivated for years to fulfill the needs of the domestic market. Up today, pepino fruit has been harvested by two visual parameters: white background color and the appearance of purple strips on the fruit (Lizana and Levano, 1977; Alvarado, 1995). However, little is known about other aspects of the fruit such as ripening behavior, and physiological and quality characteristics of pepino, leading to a poor selection and handling. As a result, pepino has been perceived with a low organoleptic fruit quality, which does not meet the consumer standards hindering the interest from the fruit industry and a potential opening to the export market (Lizana and Levano, 1977; Huyskens-Keil et al., 2001; Rodríguez-Burruezo et al., 2011).

Previous studies about the physiology and composition of the fruit have focused on parameters such as firmness (Heyes et al., 1994), organic acid, sugar and amino acid metabolisms (Redgwell and Turner, 1986; Schaffer et al., 1989; Sánchez et al., 2000; Kola et al., 2015), and susceptibility to bruise injury (Gould et al., 1990). These studies have found, for example, that carbohydrate content varied among clones, fields, and late and early crops suggesting a considerable variation in the physiology of the ripening (Sánchez et al., 2000). In addition, data on organic acids have shown citric acid to be the most prominent acid in the fruit explaining up to $90 \%$ of the non-volatile organic acids (Redgwell and Turner, 1986). Likewise, sucrose has been reported as the major sugar representing more than $50 \%$ of the sugar composition in pepino fruit. Despite all this helpful information, and to the best of our knowledge, there are only few reports on the ripening and physiological parameters of the pepino. Therefore, the main objective of this work was to study the physiological parameters and maturity of pepino fruit that may improve our knowledge about pepino fruit handling and quality.

\section{MATERIALS AND METHODS}

\section{Plant material}

Fruit from the most common pepino selection cultivated in Chile were collected between January and March 2015, and between February and April 2016, from a commercial field located in Ovalle (30³3'22.854" S, 71³8'43.004" W), Coquimbo Region, northern Chile. According to International Plant Genetic Resources Institute (IPGRI, Rome, Italy), some important pepino descriptors of this common selection include: traditional cultivar/landrace, mode of reproductionvegetative (cuttings), dessert fruit, fruit curvature- none, predominant fruit shape- ellipsoid, fruit apex shape- protruded, immature fruit color- white, and fruit predominant color at commercial harvest- pale yellow. Both years, fruit samples from six developmental stages based on fruit size and external color were studied from a very immature fruit (stage 1) to a senescent fruit (stage 6). Sound plants with similar characteristics were selected in the field, and 150 uniform pepino fruits 
were labeled approximately $10 \mathrm{~d}$ after fruit set (stage 1). Then, 25 labeled fruits were hand-picked from the field every 2-3 wk (stages 2-5) during fruit development until $\sim 90 \mathrm{~d}$ after fruit set (stage 6) (Contreras et al., 2017). The collected fruit were placed in fruit trays to avoid bruising and abrasion during transportation. The fruit was transported to the laboratory facilities by a covered ground transportation during $\sim 5 \mathrm{~h}$ at $20-25^{\circ} \mathrm{C}$, avoiding vibration damage, reducing water loss and without affecting the progression of ripening as shown in preliminary studies (Contreras et al., 2016), to the Postharvest Laboratory at INIA-La Platina in Santiago (Chile). After arrival to the laboratory, fruit were quickly selected and stored overnight at $20^{\circ} \mathrm{C}$ for analyses the next day.

Additionally, a maturity assay was carried out in 2015 season. At harvest time, fruit from the same field were collected with two different maturity stages: M1 (pepinos with green background color), M2 (pepinos with white background color), and M3 (pepinos with a yellow background color) to test quality differences in an over-ripe fruit.

\section{Physiological and quality parameters}

Quality parameters were determined for each sampling date, during development, from 20 fruit as biological replicates. The results were expressed as the standard error (SE) of the mean. Ethylene production and the respiration rate were determined using intact fruit with a static system. Briefly, fruit from developmental stage 1 were weighed and placed in $0.5 \mathrm{~L}$ jars, from stages $2,3,4$, and 5 in $0.75 \mathrm{~L}$ jars, and from stage 6 in $1.56 \mathrm{~L}$ jars, which were sealed and kept at $20^{\circ} \mathrm{C}$ for $30 \mathrm{~min}$ prior to measurements. Fruit from the maturity assay were weighed and placed in $1.56 \mathrm{~L}$ jars, stored at $20^{\circ} \mathrm{C}$ and measured every 3-4 d. The concentrations of carbon dioxide $\left(\mu \mathrm{g} \mathrm{CO} \mathrm{kg}^{-1} \mathrm{~s}^{-1}\right)$ and ethylene $\left(\mathrm{ng} \mathrm{C}_{2} \mathrm{H}_{4} \mathrm{~kg}^{-1} \mathrm{~s}^{-1}\right)$ in the jar headspace were then determined using a gas analyzer (PBI-Dansensor Checkmate 9900, Ringsted, Denmark) and a gas chromatograph (GC-8A; Shimadzu, Tokyo, Japan) equipped with a flame ionization detector (FID). The remaining fruit quality parameters were assessed with same methodology for the developmental study and maturity assay. Fruit firmness was assessed by two measurements performed on opposite sheets of peeled fruit using a penetrometer (Effegi, Milan, Italy) equipped with a $4 \mathrm{~mm}$ (at stages 3 and 4) or $8 \mathrm{~mm}$ (stages 5 and 6) plunger; the values were expressed in Newton $(\mathrm{N})$. Each fruit was subsequently halved, and one half was immediately frozen in liquid nitrogen and stored at $-20^{\circ} \mathrm{C}$ for organic acid and sugar analysis. From the other half, a sample of $10 \mathrm{~g}$ was homogenized in a mortar, and the juice was analyzed for soluble solid content (SSC) and titratable acidity (TA); SSC was measured using a temperaturecompensated refractometer (ATC-1e; Atago, Tokyo, Japan), and the value was expressed as percentage. Titratable acidity measurements were performed by titration with $0.2 \mathrm{~N} \mathrm{NaOH}$ until $\mathrm{pH} 8.2$ was reached; the values were expressed as a percentage of malic acid equivalents.

\section{Organic acids and sugar determination}

Samples of each developmental stage were prepared from frozen homogeneous fruit flesh and three replicates at each sampling time were considered. Organic acids and sugars were extracted, analyzed by HPLC and expressed in fresh weight (FW) according to the methodology described by Manríquez et al. (2014). Same methodology was carried out for the developmental study and maturity assay. Below is a brief summary of the procedure. Five grams of tissue were homogenized in an Ultra-Turrax T25 (IKA, Staufen, Germany) with $12.5 \mathrm{~mL}$ cold $95 \%$ ethanol for 3-5 min. The sample was centrifuged at $8000 \mathrm{rpm}$ for $20 \mathrm{~min}$ at $4{ }^{\circ} \mathrm{C}$ and vacuum filtered through two layers of Whatman $\mathrm{N}^{\circ} 1$ paper. The solution was brought to a $25 \mathrm{~mL}$ with $80 \%$ ethanol. Then, an aliquot of $10 \mathrm{~mL}$ was dried down under nitrogen gas in a thermal bath at $50{ }^{\circ} \mathrm{C}$. The residue was resuspended in $2 \mathrm{~mL} 0.2 \mathrm{~N} \mathrm{H}_{2} \mathrm{SO}_{4}$ with $0.05 \%$ EDTA.

The sample was loaded onto an activated sorbent cartridge (Sep-Pak plus C18; Waters, Milford, Massachusetts, USA) and the eluate collected. The eluate was filtered through a $0.45 \mu \mathrm{m}$ filter and analyzed by HPLC. For quantification, calibration curves were designed based on standards for each compound. Calibration curves for D-(-)-fructose (SigmaAldrich, St. Louis, Missouri, USA), D-(+)-glucose and sucrose (Supelco Analytical, Bellefonte, Pennsylvania, USA) were used to quantify the sugars. Calibration curves for citric acid (Supelco Analytical), quinic acid (Supelco Analytical), tartaric acid (Fluka, Seelze, Germany), D-(+)-malic acid (Fluka), L-ascorbic acid (Sigma-Aldrich), and succinic acid (Riedel-de Häen, Morristown, New Jersey, USA) were used to quantify the organic acids present in the sample.

Sugars were analyzed in a chromatograph composed of an evaporative light scattering detector (ELSD), Sedex 80 (SEDERE LT-ELSD) and an YL9100 HPLC system (YL Instruments, Anyang, Korea). The separation of sugars was performed using an amino column Kromasil 100-5-NH2 $(250 \mathrm{~mm} \times 4.6 \mathrm{~mm})$ (AkzoNobel, Bohus, Sweden) with a mobile 
phase of 95\% acetonitrile and 5\% HPLC-grade water, degassed and ultrasonicated. The analysis conditions were held constant at a flow rate of $1.5 \mathrm{~mL} \mathrm{~min}^{-1}$ for $35 \mathrm{~min}$ at $20^{\circ} \mathrm{C}$. The injection volume was $20 \mu \mathrm{L}$. The data were analyzed with software YL-Clarity version 4.0.3. (YL Instruments).

Organic acids were analyzed in a chromatograph with an ultra-violet detector UV-VIS LC-NET II/ADC (JASCO Corporation, Tokyo, Japan) to measure the absorbance at $195 \mathrm{~nm}$. The separation of acids was performed using a Symmetry C-18 $(4.6 \mathrm{~mm} \times 250 \mathrm{~mm}, 5.0 \mu \mathrm{m})$ (Waters, Wexford, Ireland). The mobile phase used was $0.0085 \mathrm{~N} \mathrm{H}_{2} \mathrm{SO}_{4}$ degassed and ultrasonicated and the analysis conditions were held constant at a flow rate of $0.4 \mathrm{~mL} \mathrm{~min}^{-1}$ for $5 \mathrm{~min}$ at $20^{\circ} \mathrm{C}$. The injection volume was $20 \mu \mathrm{L}$. The data were analyzed with ChromPass v. 1.7 software (JASCO Corporation).

\section{Volatile extraction}

Flesh with peel from pepino samples of 2015 and 2016 were analyzed. Volatiles compounds were determined only for the developmental study. A small-scale liquid/liquid extraction (LLE) method was used for the volatile analysis (Aubert et al., 2005). The extraction method and analysis of volatiles by gas chromatography-mass spectrometry (GC-MS) were performed according to the methodology described in Contreras et al. (2017).

\section{RESULTS AND DISCUSSION}

\section{Developmental experiment}

During the six stages of development spanning nearly $90 \mathrm{~d}$ after fruit set, pepino fruit showed low respiration rates, between 20-25 $\mu \mathrm{g} \mathrm{CO}_{2} \mathrm{~kg}^{-1} \mathrm{~s}^{-1}$ at immature stages down to $5 \mu \mathrm{g} \mathrm{CO}_{2} \mathrm{~kg}^{-1} \mathrm{~s}^{-1}$ at riper stages (Figure 1). Also, pepino did not show a climacteric peak after harvest coinciding with the literature that has classified this fruit as having a nonclimacteric ripening physiology (El-Zeftawi et al., 1988; Heyes et al., 1994; Ahumada and Cantwell, 1996) (Figure 1). Therefore, pepino is a non-climacteric fruit according to our data, however, we do not rule out the possibility that there may be climacteric accessions, such as the case of melon (Obando-Ulloa et al., 2008) or Asian pear (Yamane et al., 2007). The higher respiratory rates in the early developmental stages coincide with the high metabolic activity of the tissue (e.g. cell division) described for immature fruit (Wills et al., 2007). In regards to ethylene, pepino showed very low production values both years, which never exceeded $0.1 \mathrm{ng} \mathrm{kg}^{-1} \mathrm{~s}^{-1}$, except for the last developmental stage (stage 6), which corresponded to a senescent fruit where ethylene emissions are triggered by senescence rather than ripening. Other authors have classified pepino among fruit with low ethylene production (Kader, 2002).

Other quality parameters, such as SSC and TA, showed a rather stable pattern during fruit development with nonsignificant accumulation (Figure 2). Noteworthy, pepino fruit had low sugar levels around $8 \%-10 \%$, compared to

Figure 1. $\mathrm{CO}_{2}$ and ethylene production in pepino during fruit development in years 2015 and 2016.

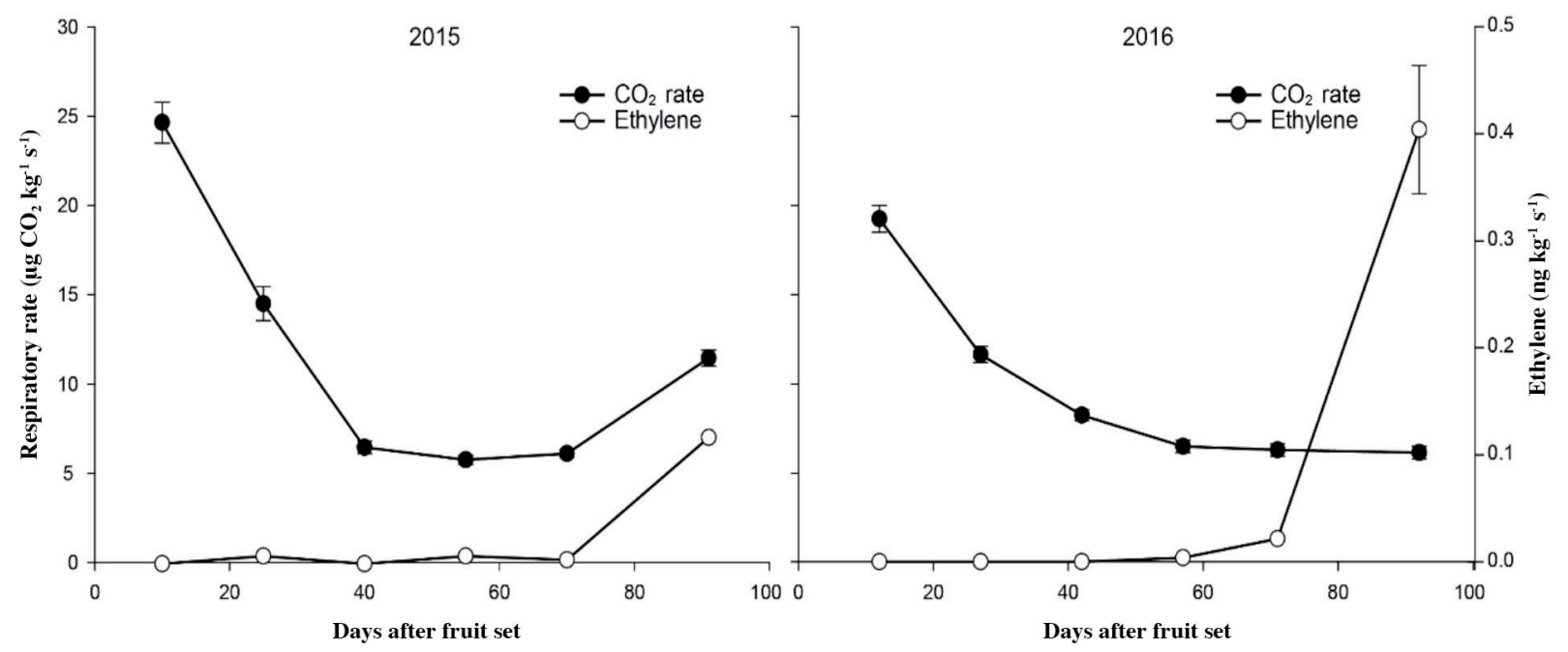

Values are means \pm standard error of 20 biological replicates. 
Figure 2. Quality parameters in pepino during fruit development in 2015 season. Physiological stage 5 corresponds to commercial harvest.

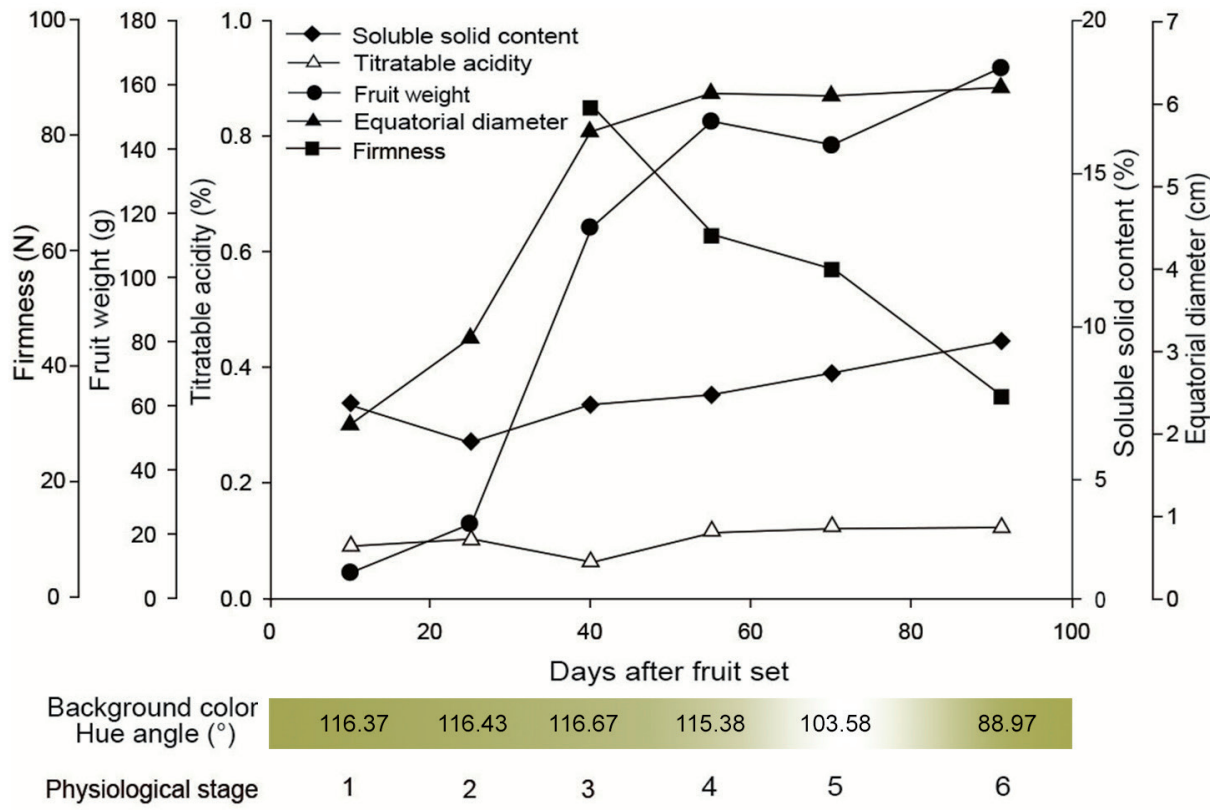

other fruit that reach 14\%-16\% (sweet cherry) and up to $>20 \%$ (table grape) of total soluble solids (Kader, 2002). Other authors have also reported little changes in SSC content after harvest, confirming that pepinos do not improve flavor after picking (Lizana and Levano, 1977; El-Zeftawi et al., 1988), and therefore, coinciding with the description of a nonclimacteric fruit which needs an optimum harvest time to ensure good quality and flavor for the consumers. Likewise, acidity stayed low, constantly around $0.1 \%$ and it was expressed in malic acid. Since pepino has been described as not particularly sweet, many medicinal applications have been reported for the fruit specially to attenuate the progression of diabetes due to its high fiber content and anti-inflammatory and antioxidant activities (Maheshwari et al., 2014).

Fruit diameter and weight were reached at early stages of development, stages 3 and 4, respectively (Figure 2). In other words, the equatorial diameter and weight were essentially completed after 40 and $50 \mathrm{~d}$ after fruit set. Schaffer et al. (1989) also studied fruit growth in pepino reporting that it completed the fruit diameter after $60 \mathrm{~d}$ post anthesis.

Fruit firmness showed an accelerated loss of flesh firmness during fruit development reaching nearly $60 \mathrm{~N}$ at stage 5 (commercial harvest) and $<40 \mathrm{~N}$ at stage 6 (senescence) (Figure 2). Other studies have reported a loss of firmness range from 60 to $<20 \mathrm{~N}$ during development, however, the developmental stages were based on background color and stripes appearance, rather than days after anthesis or fruit set making it not comparable to our study (Heyes et al., 1994). Galletti et al. (2006) reported in Chilean pepinos a firmness of 54-51 N at harvest similar to the values obtained in this study.

Color and soluble solids have been reported as harvest indices and maturity measurements (El-Zeftawi et al., 1988). The background color, which has been used as a maturity index for pepinos also changed during maturation. Hue angle decreased during fruit development moving from green color to white during harvest time, and yellow in a senescent fruit (Heyes et al., 1994). Fruit quality parameters were summarized in Table 1 for the two seasons 2015 and 2016.

The organic acids found in pepino were malic, quinic, tartaric, citric and succinic (Figure 3). Different patterns were observed for organic acid accumulation during fruit development. For instance, malic acid was decreasing throughout development whereas the concentration of succinic acid increased especially in riper pepino stages (Figure 3). In fruit from 2015, malic acid was the predominant acid, however, in 2016 fruit, its concentration decreased being the second abundant acid after quinic acid. Other studies have found malic and traces of quinic acid in 'Suma' (Redgwell and Turner, 1986). Interestingly, it has been reported in the literature on developed and established cultivars that citric acid is the predominant organic acid increasing 3-fold in riper stages and accounting for nearly $90 \%$ of the non-volatile organic acids (Redgwell and Turner, 1986; Kola et al., 2015). However, we could not confirm this result in our study, in fact, citric acid showed the lowest levels in both years. One possible explanation for this notorious difference between the 
Table 1. Quality parameters of pepino fruit during 91 and $92 \mathrm{~d}$ of fruit development for 2015 and 2016, respectively.

\begin{tabular}{lccccc}
\hline & \multicolumn{2}{c}{2015} & & \multicolumn{2}{c}{2016} \\
\cline { 2 - 3 } \cline { 5 - 6 } Quality parameters & Min & Max & & Min & Max \\
\hline Weight, g & 7.8 & 165.1 & & 8.1 & 195.1 \\
Firmness, N & 33.3 & 82.3 & & 17.6 & 78.4 \\
Background color, hue $^{\circ}$ & 88.97 & 116.67 & & 94.80 & 116.73 \\
Polar diameter, cm & 4.0 & 8.8 & & 2.1 & 10.0 \\
Equatorial diameter, cm & 2.1 & 6.2 & & 3.3 & 6.3 \\
Soluble solid content, \% & 5.4 & 8.9 & & 5.0 & 7.9 \\
Titratable acidity, \% & 0.06 & 0.12 & & 0.07 & 0.14 \\
\hline
\end{tabular}

Hue angle: $0^{\circ}$ Red; $90^{\circ}$ yellow; $180^{\circ}$ green; $270^{\circ}$ blue.

Figure 3. Organic acid concentration in pepino during fruit development in years 2015 and 2016.

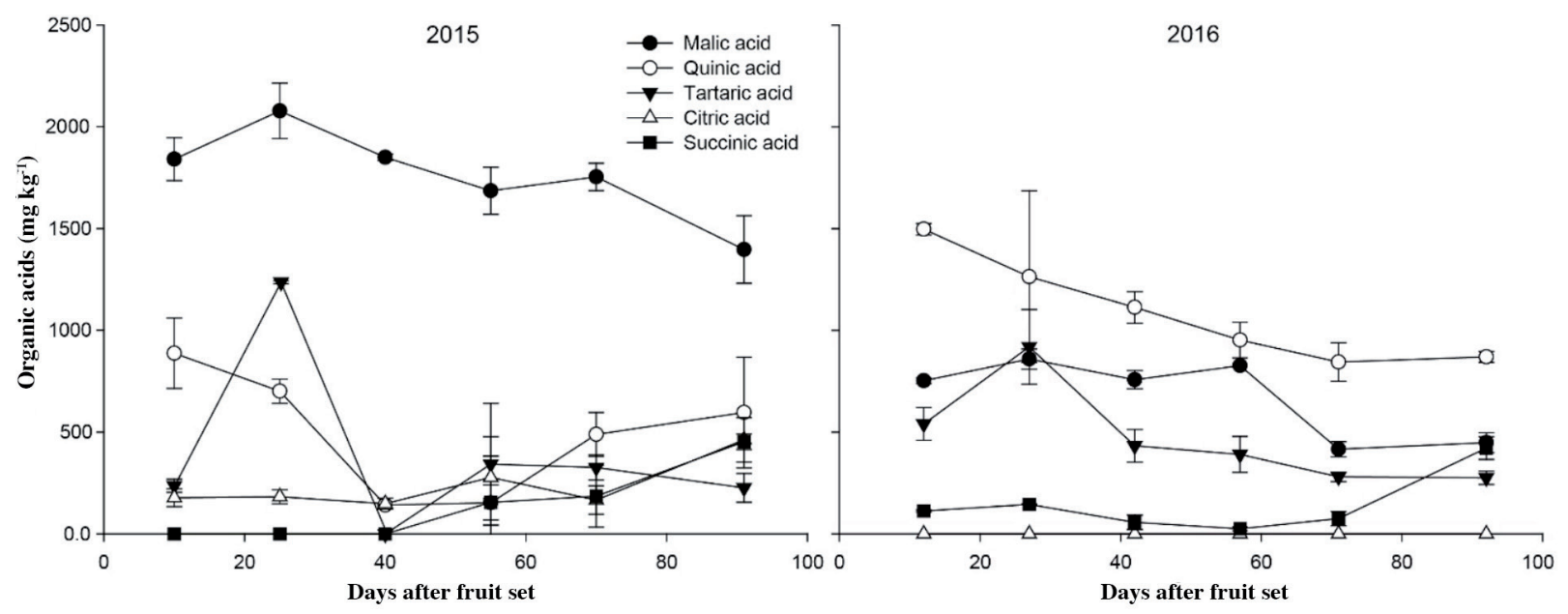

Values are means \pm standard error of three replicates. Organic acids are expressed on a fresh weight basis.

Chilean pepinos (which correspond to native accessions) and foreign developed cultivars, is that the citric acid found in developed cultivars is the result of breeding programs that targeted for improved flavor, selecting clones with increased sugar and acid concentration. This resulted in cultivars with higher levels of citric acid (Rodríguez-Burruezo et al., 2011). Regardless of this difference, it is important to note that the overall content of organic acids in pepino was very low.

In regard to sugar concentration, fructose, glucose and sucrose were the main soluble sugars as it has been found by other authors (Schaffer et al., 1989) (Figure 4). These sugars showed a similar pattern described by Schaffer et al. (1989) and Sánchez et al. (2000), where sucrose is present in low amounts during immature stages to accumulate at higher levels during ripening. Actually, sucrose has been described to account for nearly 50\% of the total sugar content (Sánchez et al., 2000). Fructose and glucose did not show significant changes throughout development, and fructose was slightly higher than glucose. Based on the physiological parameters, 2016 was a colder year since the fruit took a longer period of time to accumulate sugars and organic acids, and the total content was lower compared to 2015. It has been reported that the accumulation of sugars and organic acids are closely linked, and many environmental factors determine their content in the fruit cell, however, temperature is a key factor as it affects the vacuolar storage via several mechanisms (Etienne et al., 2013). The constant low level of sucrose observed during 2016 may be explained by the physiological age of the fruit (Figure 4). Likely, the fruit development was slower during that season due to lower temperatures taking more time for the fruit to fully ripe. It is important to note that soluble sugars do not fully account for the total SSC, since other pigments such as anthocyanins and carotenoids also contribute to the SSC (Muñoz-Robredo et al., 2011). Organic acids, on the other hand, showed decreasing levels during development both years. This behavior has been previously reported in fruit developmental studies, where sugars are the respiratory substrate in green/immature stages, but when ripening occurs there is a shift to organic acids explaining the lower levels at the senescent stage (Etienne et al., 2013). 
Figure 4. Soluble sugar concentration in pepino during fruit development in years 2015 and 2016.

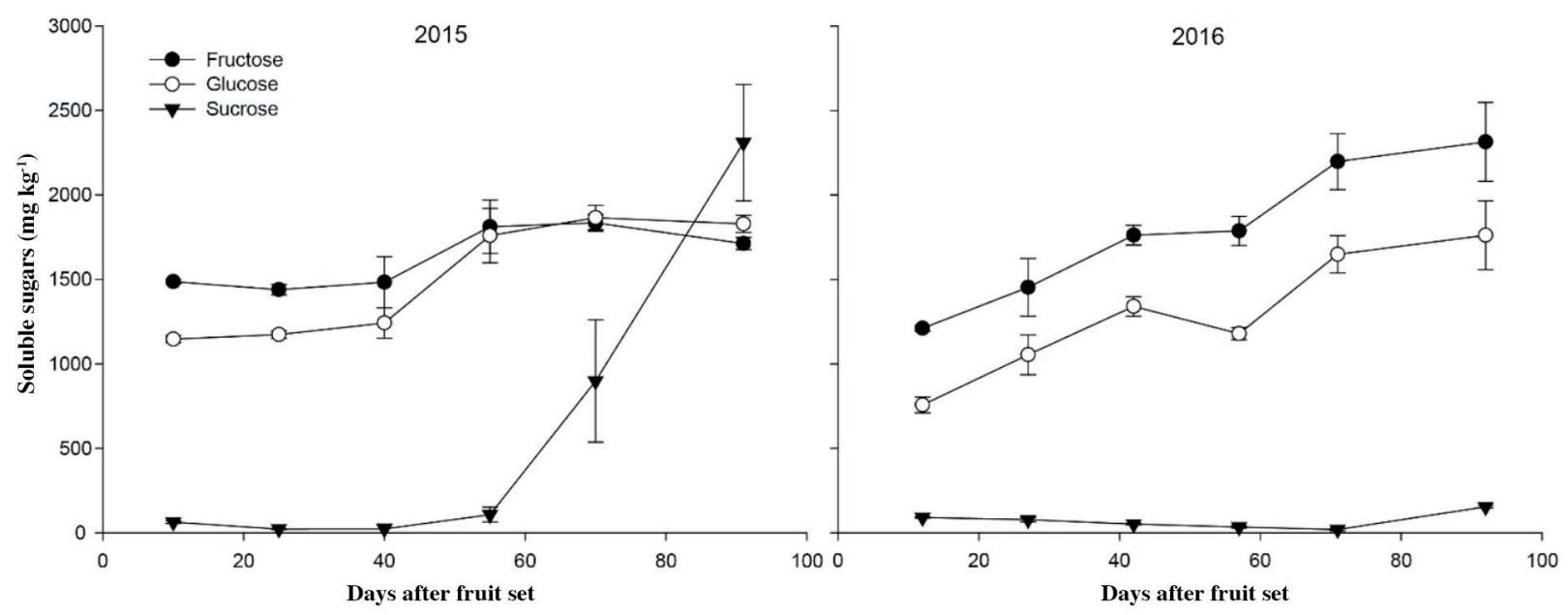

Values are means \pm standard error of three replicates. Soluble sugars are expressed on a fresh weight basis.

The volatile profile of Chilean pepinos also coincides with the literature (Shiota et al., 1988; Rodríguez-Burruezo et al., 2004a) where volatiles derived from the terpenoid pathway are the most predominant aroma constituents, followed by volatiles derived from the lipoxygenase (LOX) pathway (Figure 5). A significant volatile emission in pepino started from phenological stages 5 and 6, which correspond to commercial harvest and senescence, respectively.

The most abundant volatile produced was 3-methyl-3-butenyl acetate, followed by 3-methyl-2-butenyl acetate, which originate from the terpenoid pathway, and trans-2-hexenal from the lipoxygenase pathway (Figure 5, Table 2). The free isoprenols (3-methyl-3-buten-1-ol and 3-methyl-2-buten-1-ol) occurred in minor amounts. Shiota et al. (1988) also found the isoprenyl esters, which confer a fruity and sweet odor, as the major compounds in 'El Camino', 'Kawi' and 'Suma'. The alcohols of the above unsaturated esters (3-methyl-3-buten-1-ol and 3-methyl-2-buten-1-ol), along with butyl acetate, hexanal, 1-butanol, 3-methyl-butyl acetate and methyl 3-methyl-2-butenoate contribute significantly to the note aroma of ripe pepinos (Figure 5).

trans-2-Hexenal, a 6-C compound and the third major volatile produced, has also been reported to be produced by pepino fruit (Rodríguez-Burruezo et al., 2004a; 2004b; 2011). Actually, other C-6 compounds from the LOX pathway have also been reported, such as hexanal and hexyl acetate, as important volatiles depending on the clone or cultivar (Rodríguez-Burruezo et al., 2004a; 2004b; 2011). Five and nine-C compounds from the LOX pathway were also found (Table 2), but these were produced in very low amounts, and in the case of C-9 compounds at immature stages of

Figure 5. Aroma volatile constituents of pepino during fruit development in years 2015 and 2016.
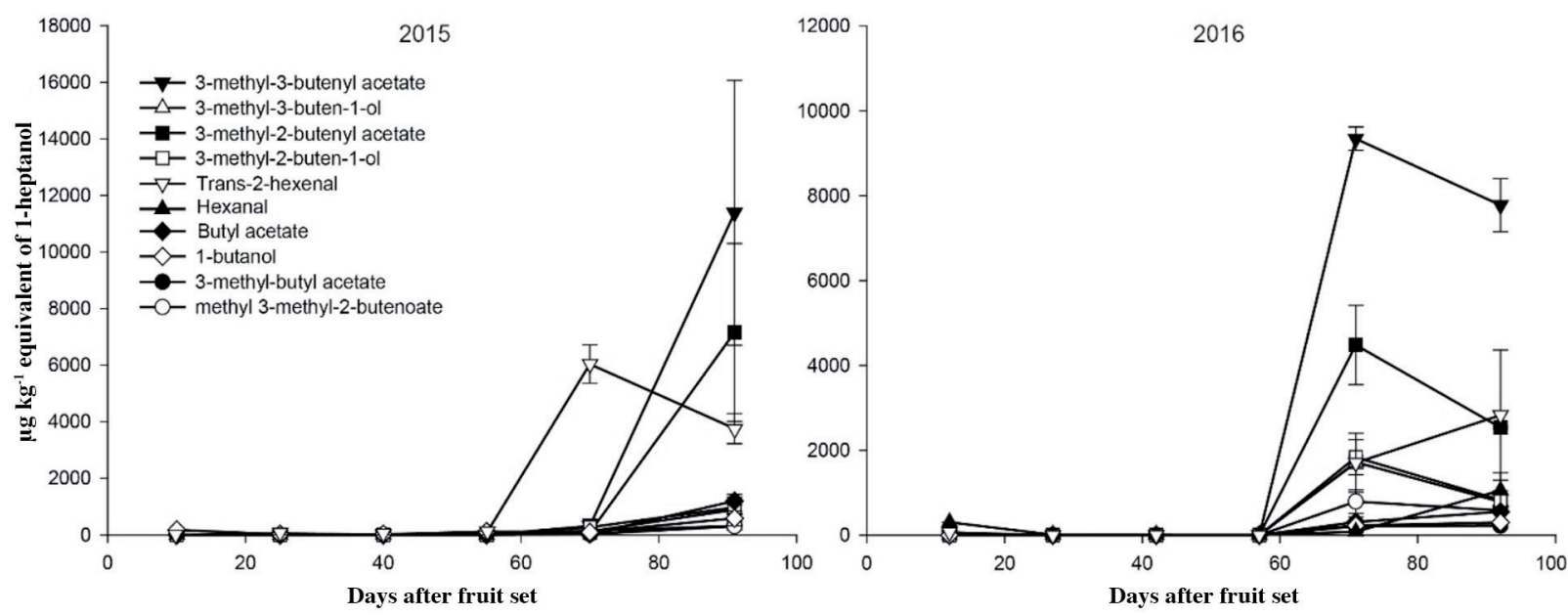

Values are means \pm standard error of five replicates. 
Table 2. Identified volatile constituents in ripe pepino fruit (stage 6) during two seasons.

\begin{tabular}{|c|c|c|c|c|}
\hline Peak & Compound & Retention time & Year 2015 & Year 2015 \\
\hline $\mathrm{Nr}$ & & $\min$ & $\mu \mathrm{g} \mathrm{kg}^{-1}$ equivalent of & f 1-heptanol \\
\hline 1 & Butyl acetate & 8.96 & 1197.96 & 550.90 \\
\hline 2 & Hexanal & 9.29 & 102.33 & 1054.46 \\
\hline 3 & 3-Methyl-butenyl acetate & 10.43 & 153.93 & 223.15 \\
\hline 4 & 1-Butanol & 10.93 & 585.00 & 300.45 \\
\hline 5 & 1-Penten-3-ol & 11.45 & 243.99 & 399.89 \\
\hline 6 & Methyl 3-methyl-2-butenoate & 11.81 & 300.71 & 583.98 \\
\hline 7 & 3-Methyl-3-butenyl acetate & 12.66 & 11386.48 & 7776.50 \\
\hline 8 & $(E)$-2-hexenal & 13.35 & 3757.54 & 4180.37 \\
\hline 9 & 3-Methyl-3-buten-1-ol & 14.34 & 887.33 & 783.59 \\
\hline 10 & 3-Methyl-2-butenyl acetate & 14.60 & 7156.74 & 2535.50 \\
\hline 11 & Hexyl acetate & 15.21 & 202.41 & nd \\
\hline 12 & 3-Methyl-2-buten-1-ol & 16.62 & 970.71 & 827.49 \\
\hline 13 & (Z)-2-Penten-ol & 16.70 & 128.15 & 242.56 \\
\hline 14 & 1-Hexanol & 17.73 & 244.83 & 346.48 \\
\hline 15 & (Z)-3-Hexenol & 18.78 & 31.33 & nd \\
\hline 16 & $(E)$-2-Hexenol & 19.51 & 666.23 & 83.57 \\
\hline 17 & (E)-2-Nonenal & 23.68 & nd & nd \\
\hline 18 & $(E, Z)-2,6$-Nonadienal & 25.25 & 21.16 & nd \\
\hline 19 & Hexanoic acid & 32.87 & $\mathrm{nq}$ & $\mathrm{nq}$ \\
\hline 20 & 2-Hexenoic acid & 35.11 & $\mathrm{nq}$ & $\mathrm{nq}$ \\
\hline 21 & Hexanoic acid & 37.67 & $\mathrm{nq}$ & $\mathrm{nq}$ \\
\hline 22 & 3-Nonenoic acid & 38.41 & $\mathrm{nq}$ & $\mathrm{nq}$ \\
\hline
\end{tabular}

nd: Not detected at ripe pepino stages; nq: not quantified.

development (Contreras et al., 2017). The C-9 compounds, which have been described in cucurbit species only, confer the cucumber-like and melon notes to the pepino fruit (Shiota et al., 1988).

Twenty-two volatile compounds were identified in pepinos by GC-MS (Table 2). Some of them were produced in higher amounts during immature stages (C-9 compounds), and others at ripe stages (C-5, C-6 and terpenes). An open question derived from this study is to identify which are the 'odor character' compounds that determine the specific pepino aroma. A preliminary study using GC-olfactometry showed that trans-2-nonenal is one of the key flavor compound in pepino (data not shown), however, further research is needed. Other authors have found that 17 odor-active volatiles (OCVs) contribute significantly to the pepino aroma and classified them in fruity (acetates), green (C-6 and C-9) and exotic (lactones, mesifuran and $\beta$-damascenone) (Rodríguez-Burruezo et al., 2004b; 2011).

\section{Maturity experiment}

There were nonsignificant differences in quality between both maturities, except in firmness (Figure 6). Respiratory rate, soluble solids and TA showed same patterns for M1 and M2 during ripening at $20^{\circ} \mathrm{C}$. As for firmness, pepino M1 (green background color) had higher firmness values than M2 (white background color) at harvest, showing a drop in firmness within $6 \mathrm{~d}$ compared to M2 which already had $<20 \mathrm{~N}$ at harvest.

Likewise, organic acids also did not show significant differences between maturities (Figure 7). In both maturities malic acid was the predominant acid and the level stayed constant about $1500-2000 \mathrm{mg} \mathrm{kg}^{-1}$ fresh weight during ripening. All other organic acids (ascorbic, quinic, tartaric, citric, and succinic) showed low concentration levels $<500 \mathrm{mg} \mathrm{g}^{-1}$.

Finally, the soluble sugar concentration also evidenced that M2 represents a more advanced physiological stage. It has been described that sucrose content increases sharply in ripe stages and then declines during over-ripe or senescent fruit (Schaffer et al., 1989). It is noticed that in M1, the sucrose content started at low level and increased until day 4 at $20^{\circ} \mathrm{C}$, then remained almost at the same levels as the other two sugars glucose and fructose, to finally increase on day 15 (Figure 8). Whereas in $\mathrm{M} 2$, the sucrose content at day 1 was also higher than the glucose and fructose level, increased until $4 \mathrm{~d}$ at $20{ }^{\circ} \mathrm{C}$ and remained constant for the rest of the storage. Likely, after the $15 \mathrm{~d}$ of storage at $20^{\circ} \mathrm{C}$ sucrose, fructose and glucose content start to decline as it has been previously reported (Schaffer et al., 1989). As for M3, with the exception of color, did not show any significant differences with M2 in any other physiological or quality parameter (data not shown). 
Figure 6. Quality parameters of pepino fruit during ripening at $20^{\circ} \mathrm{C}$. M1: Fruit with green background color, and M2: fruit with white background color.
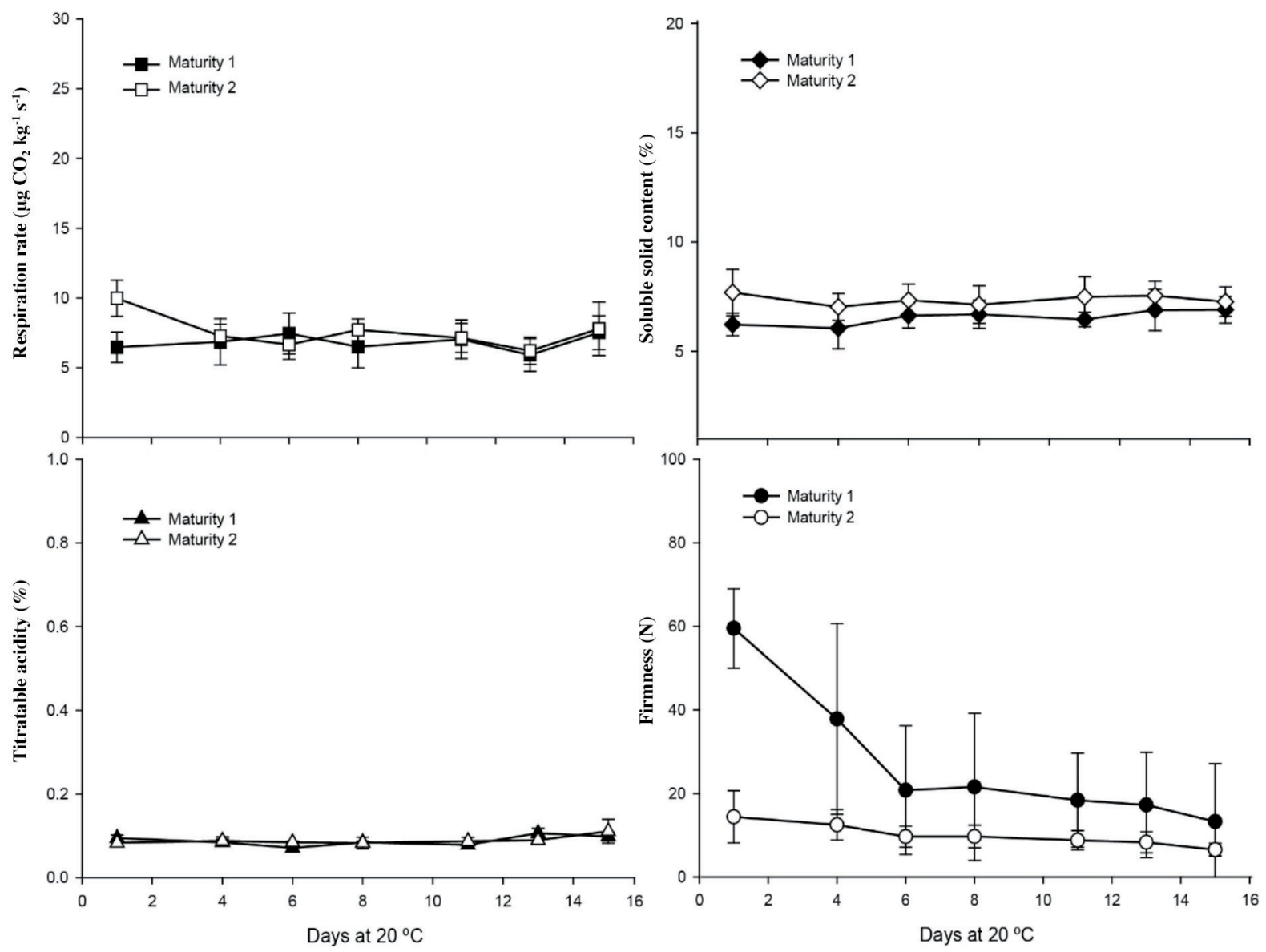

Values are means \pm standard error of 20 biological replicates.

Figure 7. Organic acid concentration in pepino fruit during ripening at $20^{\circ} \mathrm{C}$. M1: fruit with green background color, and M2: fruit with white background color.

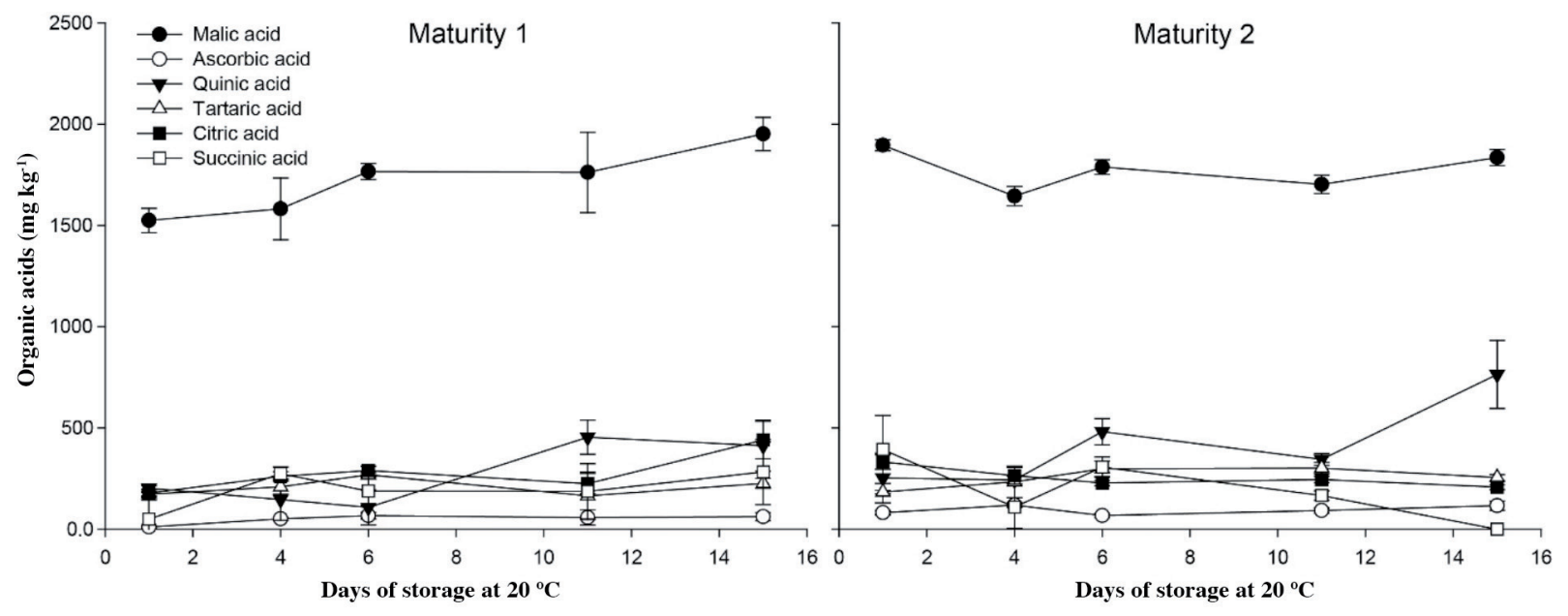

Values are means \pm standard error of three replicates. Organic acids are expressed on a fresh weight basis. 
Figure 8. Soluble sugar concentration in pepino fruit during ripening at $20^{\circ} \mathrm{C}$. M1: Fruit with green background color, and M2: fruit with white background color.

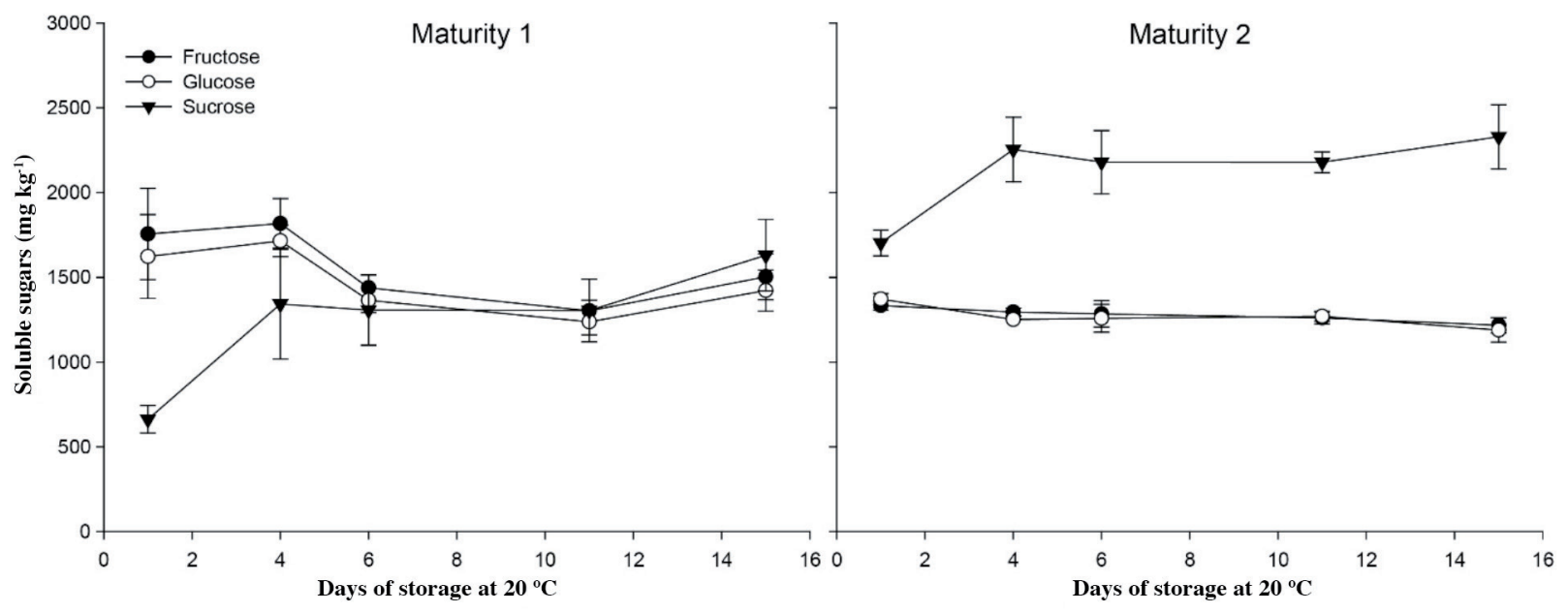

Values are means \pm standard error of three replicates. Soluble sugars are expressed on a fresh weight basis.

\section{CONCLUSIONS}

It is of great relevance the acceptability judgement that producers and consumers make when they eat a certain fruit. Hence, the importance for establishing maturity indices for harvesting and quality parameters for eating and storability so that the fruit can have a successful market life. Our study on native pepino accessions showed malic and quinic acids as the predominant organic acids, and that aroma and color are strongly induced under ripening conditions. In addition, there are nonsignificant differences between fruits with green background color (M1) and white background color (M2), except for firmness and soluble sugar contents, where M2 showed a more advanced stage of ripening. It has been recommended that soluble solid concentration and color are suitable maturity indices, our study corroborated both parameters and also suggest aroma as a harvest index. However, aroma is a quality attribute difficult to assess in the field, perhaps, in the near future an aroma device may be developed to be used as a handy tool for harvesting.

\section{ACKNOWLEDGEMENTS}

We gratefully acknowledge the financial support of CONICYT-Chile (Fondecyt grant \#3150082).

\section{REFERENCES}

Ahumada, M., and Cantwell, M. 1996. Postharvest studies in pepino dulce (Solanum muricatum Ait.): Maturity at harvest and storage behavior. Postharvest Biology and Technology 7:129-136.

Alvarado, P. 1995. El cultivo del pepino dulce. Agroeconómico Fundación Chile 30:13-18.

Anderson, G., Jansen, R., and Kim, Y. 1996. The origin and relationships of the pepino, Solanum muricatum (Solanaceae): DNA restriction fragment evidence. Economic Botany 50:369-380.

Aubert, C., Baumann, S., and Arguel, H. 2005. Optimization of the analysis of flavor volatile compounds by liquid-liquid microextraction (LLME). Application to the aroma analysis of melons, peaches, grapes, strawberries, and tomatoes. Journal of Agricultural and Food Chemistry 53: 8881-8885.

Bravo, A., y Arias, E. 1983. Cultivo del pepino dulce. El Campesino 114:15-33.

Contreras, C., González-Agüero, M., and Defilippi, B. 2016. A review of pepino (Solanum muricatum Aiton) fruit: A quality perspective. HortScience 51:1127-1133.

Contreras, C., Schwab, W., Mayershofer, M., González-Agüero, M., and Defilippi, B. 2017. Volatile compound and gene expression analyses reveal temporal and spatial production of LOX-derived volatiles in pepino (Solanum muricatum Aiton) fruit and LOX specificity. Journal of Agricultural and Food Chemistry 65:6049-6057.

El-Zeftawi, B., Brohier, L., Dooley, L., Goubran, F., Holmes, R., and Scott, B. 1988. Some maturity indices for tamarillo and pepino fruits. Journal of Horticultural Science 63:163-169. 
Etienne, A., Génard, M., Lobit, P., Mbeguié-A-Mbéguié, D., and Bugaud, C. 2013. What controls fleshy fruit acidity? A review of malate and citrate accumulation in fruit cells. Journal of Experimental Botany 64:1451-1469.

Galletti, L., Berger, H., Drouilly, D., y Lizana, A. 2006. Atmósfera modificada en fruto de pepino dulce. IDESIA(Chile) 24:35-40.

Gould, K., Hammett, K., and Steinhagen, S. 1990. Mechanism of bruise resistance in pepino (Solanum muricatum) fruit. Annals of Botany 66:155-161.

Heyes, J., Blaikie, F., Downs, C., and Sealey, D. 1994. Textural and physiological changes during pepino (Solanum muricatum Ait.) ripening. Scientia Horticulturae 58:1-15.

Huyskens-Keil, S., Prono-Widayat, H., Schreiner, M., and Peters, P. 2001. Effect of surface coating and film packaging on the keeping quality of solanaceous crops (Solanum muricatum Ait., Solanum quitoense Lam.) Acta Horticulturae 553:621-625.

IPGRI and COMAV. 2004. Descriptors for Pepino (Solanum muricatum). International Plant Genetic Resources Institute (IPGRI), Rome, Italy, and Centro de Conservación y Mejora de la Agrodiversidad Valenciana (COMAV), Valencia, Spain .

Kader, A. (ed.) 2002. Quality and safety factors: Definition and evaluation for fresh horticultural crops. p. $279-285$. Postharvest technology of horticultural crops. $3^{\text {rd }}$ ed. University of California Agriculture and Natural Resources, Oakland, California, USA.

Kola, O., Simsek, M., Duran, H., and Bozkir, H. 2015. HPLC determination of carotenoid, organic acid, and sugar content in pepino (Solanum muricatum) fruit during the ripening period. Chemistry of Natural Compounds 51:132-136.

Levy, D., Kedar, N., and Levy, N. 2006. Pepino (Solanum muricatum Aiton): Breeding in Israel for better taste and aroma. Israel Journal of Plant Science 54:205-213.

Lizana, L., y Levano, B. 1977. Caracterización y comportamiento de post-cosecha del pepino dulce Solanum muricatum. Ait. Proceedings Tropical Region American Society for Horticultural Science 21:11-15.

Maheshwari, R., Malhorta, J., Mohan, L., and Upadhyay, B. 2014. Exotic pepino: A shrub for prophylactic consequence and nutritional regime. International Journal of Pharma Research and Health Sciences 2:42-48.

Manríquez, D., Muñoz, P., Gudenschwager, O., Robledo, P., and Defilippi, B. 2014. Development of flavor-related metabolites in cherimoya (Annona cherimola Mill.) fruit and their relationship with ripening physiology. Postharvest Biology and Technology 94:58-65.

Morley-Bunker, M.J.S. 1983. A new commercial crop, the pepino (Solanum muricatum Ait.) and suggestions for further development. Annual Report of the Royal New Zealand Institute of Horticulture 11:8-19.

Muñoz-Robredo, P., Robledo, P., Manríquez, D., Molina, R., and Defilippi, B. 2011. Characterization of sugars and organic acids in commercial varieties of table grapes. Chilean Journal of Agricultural Research 71:452-458.

National Research Council. 1989. Lost crops of the Incas: Little-known plants of the Andes with promise for worldwide cultivation: Introduction. National Academy Press, Washington D.C., USA.

Obando-Ulloa, J., Moreno, E., García-Mas, J., Nicolai, B., Lammertyn, J., Monforte, A., et al. 2008. Climacteric or nonclimacteric behavior in melon fruit. 1. Aroma volatiles. Postharvest Biology and Technology 49:27-37.

Prohens, J., Ruiz, J., and Nuez, F. 1996. The pepino (Solanum muricatum, Solanaceae). A "new" crop with a history. Economic Botany 50:355-368.

Redgwell, R., and Turner, N. 1986. Pepino (Solanum muricatum): Chemical composition of ripe fruit. Journal of the Science of Food and Agriculture 37:1217-1222.

Rodríguez-Burruezo, A., Kollmannsberger, H., Prohens, J., Nitz, S., and Nuez, F. 2004a. Analysis of the volatile aroma constituents of parental and hybrid clones of pepino (Solanum muricatum). Journal of Agricultural and Food Chemistry 52:5663-5669.

Rodríguez-Burruezo, A., Prohens, J., and Fita, A. 2011. Breeding strategies for improving the performance and fruit quality of the pepino (Solanum muricatum): A model for the enhancement of underutilized exotic fruits. Food Research International 44:1927-1935.

Rodríguez-Burruezo,A., Prohens, J., and Nuez, F. 2004b. 'Valencia': A new pepino (Solanum muricatum) cultivar with improved fruit quality. HortScience 39:1500-1502.

Sánchez, M., Camara, M., Prohens, J., Ruiz, J., Torija, E., and Nuez, F. 2000. Variation in carbohydrate content during ripening in two clones of pepino. Journal of the Science of Food and Agriculture 80:1985-1991.

Schaffer, A., Rylski, I., and Fogelman, M. 1989. Carbohydrate content and sucrose metabolism in developing Solanum muricatum fruits. Phytochemistry 3:737-739.

Shiota, H., Young, H., Paterson, V., and Irie, M. 1988. Volatile aroma constituents of pepino fruit. Journal of the Science of Food and Agriculture 43:343-354.

Wills, R., McGlasson, B., Graham, D., and Joyce, D. 2007. Evaluation and management of quality. p. 159-187. In Will, R. (ed.) Postharvest: An introduction to the physiology and handling of fruit, vegetables and ornamentals. University of New South Wales Press, Sydney, Australia.

Wratt, G., and Smith, H. 1983. Plant breeding in New Zealand. 309 p. Butterworths, New Zealand Department of Scientific and Industrial Research, Wellington.

Yamane, M., Abe, D., Yasui, S., Yokotani, N., Kimata, W., Ushijima, K., et al. 2007. Differential expression of ethylene biosynthetic genes in climacteric and non-climacteric Chinese pear fruit. Postharvest Biology and Technology 44:220-227. 